Int. J. Electrochem. Sci., 15 (2020) 1606 - 1621

\title{
Polystyrene Sulfonic Acid-Doped Polypyrrol (dppy) as a Corrosion Inhibitor for Carbon Steel in 1.0 M HCl Solution
}

\author{
Xiumei Wang*, Jiani Xing \\ School of Materials Science and Engineering, Shenyang Jianzhu University, Shenyang, Liaoning, \\ China 110168 \\ "E-mail: xmwang@alum.imr.ac.cn
}

doi: $10.20964 / 2020.02 .46$

Received: 18 October 2019 / Accepted: 8 December 2019 / Published: 31 December 2019

\begin{abstract}
The inhibition performance of doped polypyrrol (dppy) for carbon steel corrosion in $1.0 \mathrm{M} \mathrm{HCl}$ solution was investigated and analyzed by weight loss method, electrochemical techniques and SEM micrographs. The results denote that both the concentration of dppy and the experimental temperature enhance the inhibitive efficiency, and the highest inhibitive efficiency is $87.1 \%$ at $40 \mathrm{mg} \mathrm{L}^{-1}(333 \mathrm{~K})$ based on the weight loss results. Dppy hinders both anodic and cathodic processes simultaneously by removing water molecules through stronger adsorption, and the self-corrosion potential $(E)$ exhibits almost no change with the increasing dppy concentration, suggesting dppy is a mixed-type corrosion inhibitor. Dppy is adsorbed on the carbon steel surface by mixed physisorption and chemisorption. The dppy adsorption conforms to the Langmuir isotherm model, and the adsorption is a spontaneous, endothermic process with an increase in entropy.
\end{abstract}

Keywords: Corrosion Inhibitor; Doped Polypyrrol (dppy); Carbon Steel; 1.0 M HCl Solution; Electrochemical Technique

\section{$\underline{\text { FULL TEXT }}$}

(C) 2020 The Authors. Published by ESG (www.electrochemsci.org). This article is an open access article distributed under the terms and conditions of the Creative Commons Attribution license (http://creativecommons.org/licenses/by/4.0/). 